\title{
With grit to innovative teams?
}

\section{A theoretical model to examine team grit as a team innovation competence}

\author{
Valeria Bernardy $^{1}$ (D) C Conny H. Antoni ${ }^{1}$ (D) \\ Accepted: 2 January 2021 / Published online: 19 January 2021 \\ (c) The Author(s) 2021
}

\begin{abstract}
This article in the Journal Gruppe. Interaktion. Organisation. (GIO) develops a theoretical model for the emergence of team grit, i.e. the competence to pursue long-term goals with passion and perseverance. We examine the role of team grit for today's dynamic innovation processes, building on findings from research on individual grit. Our model shows how team inputs as well as the dynamic interaction of team processes and affective and cognitive emergent states lead to the emergence of team grit and thus promote team innovation. We explore contagion and crossover processes as mechanisms for team grit to emerge, and examine team processes that we assume to affect team grit. Our model not only provides a starting point for further research on team grit, but also provides practitioners with recommendations to foster team grit in order to improve their innovative performance in the team.
\end{abstract}

Keywords Team Grit · Team Competences · Team Innovation · Emotional Contagion · Team Processes

\section{Mit Grit zu innovativen Teams?}

Ein theoretisches Modell zur Untersuchung von Team Grit als Innovationskompetenz von Teams

\section{Zusammenfassung}

In diesem Beitrag der Zeitschrift Gruppe. Interaktion. Organisation (GIO) entwickeln wir ein theoretisches Modell für die Emergenz von Team Grit (,Biss“), der Kompetenz langfristige Ziele mit Passion und Beharrlichkeit zu verfolgen. Aufbauend auf der Forschung zu individuellem Grit, beleuchten wir die Rolle von Team Grit im Rahmen von heutigen dynamischen Innovationsprozessen. Unser Modell zeigt auf, wie Team Inputs sowie das dynamische Zusammenspiel von Teamprozessen und affektiven und kognitiven emergenten Zuständen zum Entstehen von Team Grit führen, und darüber Team Innovation fördern. Wir untersuchen Ansteckungs- und Crossover-Prozesse als Mechanismen, durch die Team Grit entsteht, und erörtern Teamprozesse, die Team Grit beeinflussen. Damit dient unser Modell nicht nur als Ansatzpunkt für die weitere Erforschung von Team Grit, sondern liefert darüber hinaus Praktikern Empfehlungen, wie Team Grit gefördert werden kann, um die innovative Leistung im Team zu stärken.

Schlüsselwörter Team Grit · Team Kompetenzen · Team Innovation · Ansteckungsprozesse · Teamprozesse

\section{The case for gritty teams in innovation processes}

Dipl.-Psych. Valeria Bernardy

bernardy@uni-trier.de

1 Abteilung für Arbeits-, Betriebs- und Organisationspsychologie, Universität Trier, 54296 Trier, Germany
Many of life's failures are people who did not realize how close they were to success when they gave up. (Thomas Alva Edison) 
Seeing innovations through until their completion can be lengthy and strenuous processes, inevitably filled with setbacks and difficulties on the way (Rousseau et al. 2013). Today's uncertain and volatile working environment adds to the complexity faced during such processes. Lending credence to the words of Thomas Edison, many innovations do not come true due to people giving up too early. In today's business environment, a company's competence to innovate is one of its most important competitive factors though (Howard and Crayne 2019; Park et al. 2018). When picturing Edison working on his innovations, many miss the fact that Edison did not work on his own, but actually worked with a team of people. As Steve Jobs once stated, "Great things in business are never done by one person. They're done by a team of people". As most of today's innovations are taken care of by teams (Hülsheger et al. 2009), understanding what competence distinguishes teams that are able to see through innovation processes until the end and handle difficulties and setbacks in the course of those, from teams that give up, is pivotal to ensure the success of innovations.

The pursuit of long-term goals with passion and perseverance in the face of adversities has been termed grit by Duckworth et al. (2007). Gritty individuals stick to their goals when others give up, in particular in challenging situations (Lucas et al. 2015). Research demonstrates the relevance of grit for achievement in well-defined performance settings (Duckworth et al. 2007). Some first studies also hint to its relevance in innovation contexts, often involving rather ill-defined goals without clear pathways for goal attainment. Grohman et al. (2017) found a positive relationship between grit and creativity, which is associated with the idea generation phase of innovation processes, when grit is needed to keep on coming up with new ideas for solving so far ill-defined problems. Mooradian et al. (2016) linked grit to innovative company performance in a sample of entrepreneurs, pointing to its relevance for the whole innovation process. Although the predominant working units in innovation processes are teams, grit has not been defined and examined yet on the team level. The lack of knowledge on the relevance of grit on the team level has led to calls to its investigation (Jordan et al. 2019).

Our article explores team grit as a team's competence to pursue long-term goals with passion and perseverance in the face of obstacles and setbacks. We propose this competence to be particularly relevant for the requirements of today's working environment, characterized by the pressure to innovate. Our aim is to develop a theoretical model of the emergence of team grit that will serve as a starting point for research on team grit. In order to do so, we first review and discuss the current state of research on grit at an individual level and its relation to creativity and innovation. Building on this, we clarify the meaning of team grit and its particular relevance in the innovation context. We discuss what distinguishes gritty from non-gritty teams and under what conditions this differentiation becomes most evident. Defining team grit as an emergent team phenomenon, we examine how team grit develops. On the foundation of the crossover model (Westman 2001) and the literature on contagion processes (Barsade 2002; Hatfield et al. 1993; Paulsen and Kauffeld 2016), we look at mechanisms that can trigger team grit to arise. Finally, building on the literature on work teams and work team emergent phenomena, we specify the team processes, which we assume to support building team grit. Besides providing a starting point for scholars to investigate team grit, our conceptual work provides practitioners with tangible measures to foster team grit.

\section{State of research: What we know about grit on the individual level}

Whereas disappointment or boredom signals to others that it is time to change trajectory and cut losses, the gritty individual stays the course. (Duckworth et al. 2007, p. 1088)

Grit is still a relatively young concept, but has quickly gained popularity because of its tangible relevance for today's requirements at school and work (Credé 2018; Jordan et al. 2019). Grit is defined as "perseverance and passion for long-term goals" (Duckworth et al. 2007, p. 1087) and entails "working strenuously toward challenges, maintaining effort and interest over years despite failure, adversity, and plateaus in progress" (Duckworth et al. 2007, p. 1088). Duckworth posited grit to include two subordinate facets: Passion (specified later as a Consistency of Interests) and Perseverance (of Effort). Gritty individuals thus combine the competence to sustain effort toward long-term goals despite the presence of setbacks and distress, with the competence to focus on a passion and exert dedicated time, attention and commitment toward long-term goals (Disabato et al. 2018; Perkins-Gough 2013). This combination of passion with perseverance and the focus on meaningful longterm goals distinguishes grit from similar constructs such as goal commitment, hardiness or conscientiousness (Jordan et al. 2019).

Empirical evidence for grit points to its relevance particularly in the pursuit of challenging goals. Thus, grit predicts retention of novice teachers in low-income districts (Robertson-Kraft and Duckworth 2014), retention of Military cadets throughout their first year of training (Duckworth and Quinn 2009) or persistence on difficult tasks (Lucas et al. 2015). Prior research has also shown a positive correlation with work engagement as well as higher educational achievement (Duckworth et al. 2007; Suzuki et al. 
2015). Despite these findings, grit has undergone scrutiny, as several studies failed to show its predictive validity (Disabato et al. 2018; Rimfeld et al. 2016). Furthermore, the higher-order structure combining the two facets perseverance and passion has been questioned (Credé et al. 2017; Credé 2018), as several studies found perseverance to be positively related to success, while the findings with regard to passion remain controversial (Grohman et al. 2017). Recent papers emphasize the importance of passion in grit, and attribute the inconsistent results to the currently used grit scale failing to capture grit's emotional underpinnings and context-specifity of passion (Jordan et al. 2019).

\subsection{Research on the development of grit}

These recent discussions on grit have led scholars to address the theoretical shortcomings of grit. Specifically addressing grit in the work context, Jordan et al. (2019) developed a work motivation conceptualization of grit in organizations. The authors' model sheds light on to the development of grit, tying it to goal-setting theory. They describe grit as both trait-like and malleable over time (Jordan et al. 2019). Their model posits grit to be context-specific and purposedriven, influencing long-term goal setting and task strategy (short-term goal) adaptation. Thus, the authors follow Duckworth and Gross (2014) conceptualization of goals being organized in a goal hierarchy, with lower-order goals serving higher-order goals. While lower-order goals are more numerous, short-term and substitutable, higher-order goals are typically fewer in number, more long-term and more meaningful and therefore less substitutable (Duckworth and Gross 2014). Within this conceptualization, grit entails having a dominant higher-order goal with tightly aligned lower-order goals, the fulfillment of which brings the gritty individual closer to achieving the higher-order goal. Jordan et al. (2019) posit in their model that in order for gritty individuals to stick to their higher-order goal, they adapt their lower-order goals when they encounter setbacks or difficulties. Not only though does grit influence how goals are set and pursued, but also does the goal setting and adaptation process help grit grow (Jordan et al. 2019). This assumption is based on the reasoning that through learning how to handle setbacks, one develops confidence in attaining goals. Grit is stimulated and further developed by learning to differentiate between lower-level goals that can be quickly abandoned and those higher-order goals (Duckworth 2016; Jordan et al. 2019).

There is also empirical evidence pointing to the malleability of grit. An intervention study found that teachers could successfully promote their students' grit by strengthening their Growth Mindset during the course of the year (Alan et al. 2019), and an experimental study showed the experience of just observing another person's gritty behav- ior to influence one's own gritty behavior (Gerhards and Gravert 2016). These first results render grit a potentially attractive target for interventions and development measures. However, the operationalization of grit in these studies is closer to perseverance than to grit as the unique combination of passion and perseverance. It remains to be tested whether and how the passion facet of grit can be developed. Due to the proposed context-specifity of grit, we expect interventions to stimulate grit that succeed in activating the 'psychological assets' of gritty individuals we describe in the next step.

Interventions to develop grit could target the four 'psychological assets' of gritty individuals postulated by Duckworth (2016): (1) interest, (2) (deliberate) practice, (3) purpose, and (4) hope. (1) Interest implies that gritty individuals intrinsically enjoy what they do. The immersion in the goal domain represents a key route through which the combination of passion and perseverance promotes higher performance (Jachimowicz et al. 2018). (2) As a mediating mechanism for gritty individuals to become higher achievers, Duckworth proposed the deliberate practice they engage in. This idea builds on the research by Ericsson (Ericsson et al. 1993) on world-class performers who were found to engage in thousands of hours of training to acquire their skills (Duckworth et al. 2011). Deliberate practice entails continuously setting oneself challenging short-term goals designed to improve performance, and continuously adapting existing task strategies based on the feedback received on prior performance. Duckworth et al. (2011) confirmed this mediating mechanism of deliberate practice in a longitudinal study investigating high achieving children in a spelling competition. (3) Purpose relates to the higherorder goal gritty people pursue. Duckworth (2016, p. 145) defines purpose as the idea that "what we do matters to people other than ourselves". She argues that gritty individuals know their purpose and this purpose represents an energizing motivator for behavior, giving individuals and thus grit a direction. Empirical evidence for the claim of purpose being strong in gritty individuals comes from a longitudinal study by Hill et al. (2016) who showed purpose to be a predictor of grit. (4) Duckworth defines hope as resting "on the expectation that our own efforts can improve our future", and which according to her "has nothing to do with luck and everything to do with getting up again" (Duckworth 2016, p. 169). This definition resembles the concept of self-efficacy in the face of difficulties and setback. Selfefficacy was found to correlate with grit, in particular the perseverance facet of grit (Muenks et al. 2018), lending first empirical support to the assumption of gritty individuals typically possessing hope. 


\subsection{Research linking grit to innovation}

So far, grit has been primarily examined with regard to difficult, but rather well-defined tasks. However, first studies linking it to innovation hint to its relevance for the rather ill-defined goals often involved in innovation processes (Grohman et al. 2017; Mooradian et al. 2016), which "often involve two steps forward for one step backwards plus several side steps" (Anderson et al. 2014, p. 1299). Individuals working on innovations need to be persistent, as innovation processes can take months or even years to realize and often involve setbacks and difficulties (Rousseau et al. 2013). Innovation processes comprise two phases: the idea generation and the idea implementation phase (Hammond et al. 2011; Hülsheger et al. 2009). Empirical results support that grit is helpful in both phases. With respect to the idea generation phase a study with a student sample shows a relation between creativity and (teacher rated) passion and perseverance (Grohman et al. 2017). Also, research on the "Dual Pathway to Creativity Model", which assumes that situational and dispositional variables lead to creative ideas via cognitive flexibility and cognitive persistence, provides empirical support that cognitive persistence leads to creative ideas (Baas et al. 2013; Nijstad et al. 2010).

With respect to idea implementation, Mooradian et al.'s (2016) study on entrepreneurs confirmed the relation between perseverance and innovation success, but not for passion. This could be due to the grit scale not capturing passion as theorized, as has been criticized by recent papers (Grohman et al. 2017; Jachimowicz et al. 2018; Jordan et al. 2019). The items representing passion in the grit scale rather measure attentional focus, neglecting the context-specifity and affective aspect of grit, which might be particularly relevant for innovation success in an entrepreneur setting (Amabile et al. 1994; Amabile and Pratt 2016). Although no causal relation can be assumed from Mooradian et al.'s (2016) study due to the cross-sectional design of the study, the results hint to grit's - or at least perseverance's-relevance for the whole innovation process, including the implementation phase. Further research distinguishing the innovation phases and paying attention to the measurement of the passion facet is needed to investigate this assumption.

To sum up, research on grit has focused on the individual level so far, and first results hint to grit's relevance for the innovation process and to its malleability. Given that typically teams of people instead of individuals are responsible for innovation processes, we explore grit in the following section at the team level, which is a gap in the literature on grit so far (Jordan et al. 2019). We will define team grit, and will then discuss how team grit develops, and what kind of team processes affect team grit and in the consequence, team innovation.

\section{Team grit and its relevance for team innovation processes}

Working in a team as compared to working individually requires team members to coordinate and synchronize their actions when striving towards a common goal, given the inherent task interdependence of teamwork (Costa et al. 2014; Stoverink et al. 2020). We define team grit as a team's competence to pursue common long-term goals despite adversities with passion and perseverance. A team with a high level of team grit stays the course, maintaining interest and effort for longer periods of time, no matter what. Based on the conceptualization of grit at the individual level, we assume team grit to be a construct with two sub-dimensions, encompassing team passion and team perseverance. Team passion stands for a high level of commitment towards a common goal, and is reflected in the fact that team members encourage each other to stay focused on what is important for the team to strive towards. Team perseverance represents a strong willingness to exert effort towards the team's common goal and not give up despite difficulties. This is manifested in the fact that when facing challenges or plateaus in progress, team members motivate each other to try another time, explicitly expressing the conviction that the effort is worthwhile.

Team grit comes into play in situations when teams work on long-term projects or tasks that require pursuing goals over a longer period of time, inadvertently involving difficulties and setbacks. Innovation processes fit that description and thus should be affected by whether teams develop team grit or not. Gritty teams are characterized by being passionate about their goal, a characteristic also considered a relevant component in theories of creativity and innovation (Amabile and Pratt 2016). This leads them to explore the target area in depth, not becoming bored, not getting sidetracked and not losing sight of their long-term goal when facing difficulties. They follow through with perseverance, not being easily discouraged by setbacks, not giving up on their goal for an "easier" one, willing to exert extra effort and finding alternative ways to reach that goal. A team high in team grit has the competence to quickly evaluate the added value of new topics for their goal and hence to decide whether to pursue it and invest energy. It also knows when to adjust its' task strategies in order to reach the long-term goals, thus showing flexibility on the path (Jordan et al. 2019). Those characteristics render the team likely to not only persist in creating qualitatively high ideas, but also to follow through with their realization, resulting in a higher team innovation.

To clarify how passion and perseverance show in teams pursuing a long-term goal requiring innovative performance imagine the following scenario, describing two fictitious teams - one high and the other low on team grit. 


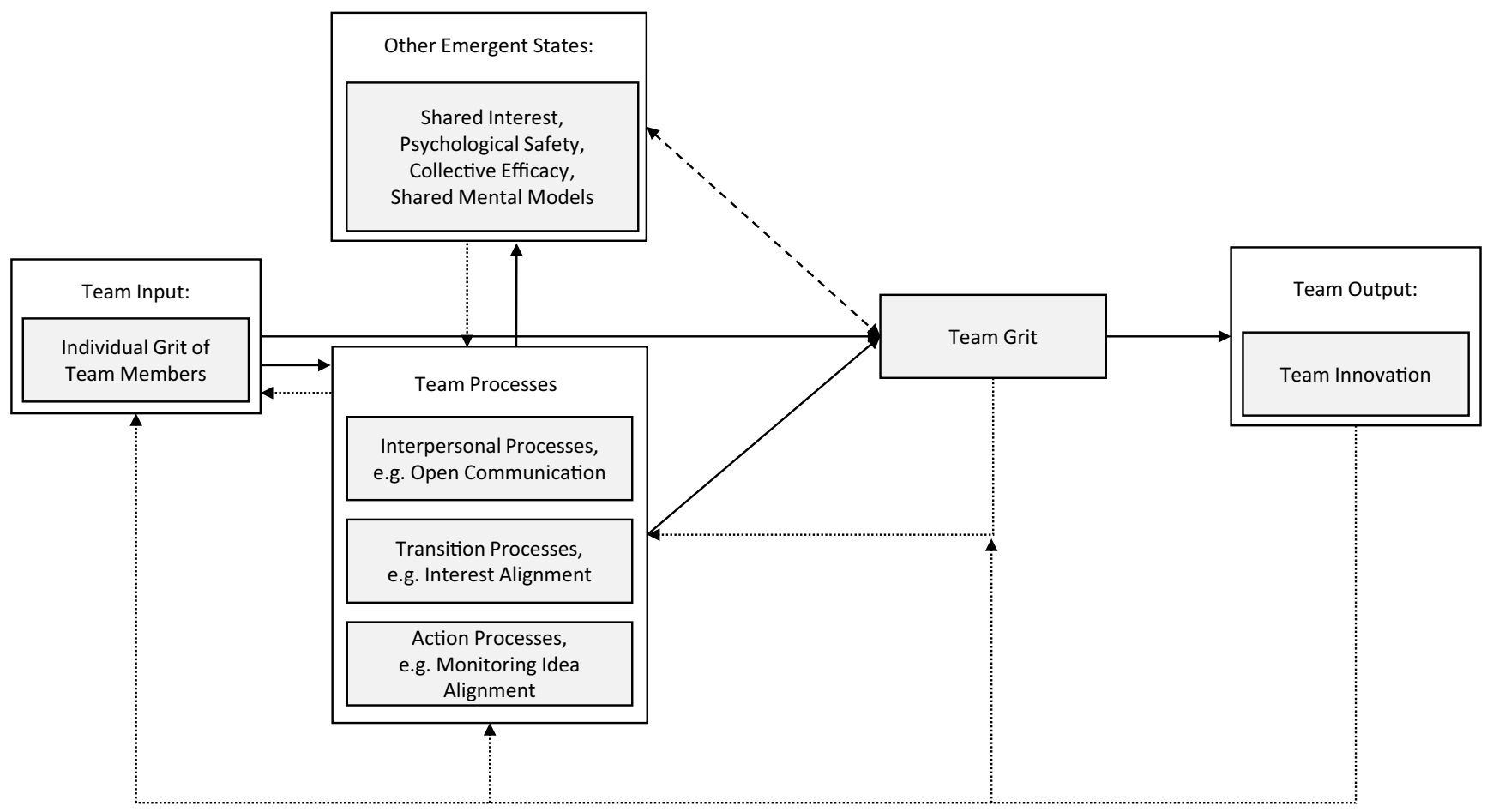

Fig. 1 The emergence of team grit. Solid arrows signal direct effects, dotted arrows signal feedback loops and dashed arrows signal a correlational relationship

In an HR organization of a company, two teams work on a project setting up the onboarding program for new employees at two business units, respectively. They do not have many restrictions and are given the freedom to be innovative. When their manager describes how she experienced both teams and how they approached the task at hand, differences become apparent. When generating ideas, both teams initiated brainstorming sessions. While Team B quickly settled on some ideas they found worthwhile pursuing, Team A went on generating ideas even after they already had some solid ones on paper and in the end came up with more original and thought-through ideas. The manager recalls Team A to have seemed enjoying their task, being deeply interested which resulted in them being curious, trying to explore as much as they could in order to grow their expertise. They never seemed to have enough answers, always eager to dig deeper, never getting bored and never getting sidetracked. When they started working on their first idea-developing a buddy-program — the feedback on their first draft involved quite a few negative points. Instead of becoming discouraged, but still being convinced that their buddy program was at its core a good idea, they took in the feedback and changed elements of the program accordingly, putting in extra effort to improve their idea. Team B on the other hand gave up on their first idea entirely after they had also received some negative feedback, not believing that it was worth to invest more time. With their end product, Team B also left some parts of their idea unfinished, only superficially closing up the project, while Team A would have gone even further, still being passionate about the project.

Considering team grit as a shared motivational emergent state that comprises affective and cognitive components, we propose a theoretical model, which describes how team grit emerges, leading to team innovation as the team output (cf. Fig. 1). Our model is based on the input-mediator-outputinput framework (IMOI; Ilgen et al. 2005). As innovations typically involve iterative processes (Rousseau et al. 2013), we assume teams going through a series of IMOI episodes over time. Team innovation of one series will probably function as a team input for the next circle (Costa et al. 2014; Marks et al. 2001). We assume the individual level of grit of each team member to influence team grit via team processes and emergent states. Team grit itself acts as the mediating mechanism for team innovation. Furthermore, we assume reciprocal effects with regard to the other emergent states to take place. The same team processes that affect team grit most probably also affect other emergent states in a dynamic and recursive way. Simultaneously, gritty teams may behave in ways that foster those other emergent states.

Describing team grit as an emergent state takes into consideration the complex interplay of team inputs, processes, outputs, and reflects its dynamic nature, departing it from the weighted sum of individual's grit (Costa et al. 2014; Kozlowski et al. 2013). Therefore, team members' individual grit might differ from team members' perception of 
their team grit. For example, a team member might have low self-efficacy affecting his/her perseverance. In the team though, the motivating behavior of his/her colleagues and them expressing the belief in the team's abilities results in his/her perception of a high collective efficacy contributing to a high team perseverance. Further, considering team grit as a shared state implies that team members have similar perceptions of the level of team grit (Costa et al. 2014). In our example, Team B quickly settled on some ideas they found worthwhile pursuing and gave up on their first idea entirely after they had also received some negative feedback. Hence, all team members would probably agree to rate their team grit quite low. By contrast, all members of Team A would probably agree to rate their team grit quite high.

In team settings, the individual grit of team members can be considered a team input variable, as the own tendency for grit might render individuals to be more prone to develop team grit (Costa et al. 2014). By no means do we claim the individual grit of team members being the sole team input influencing team grit. Nonetheless, we argue that the emergence of team grit is linked to the individual team member's grit, which we assume to give rise to emotional contagion and crossover effects that we assume to be a key mechanism for the emergence of team grit, and which we will examine further in the next section. Beside the team inputs, we assume the emergence of team grit to be essentially linked to team processes as well as related emergent states, which we will explore in the section thereafter.

\subsection{Emotional contagion and crossover effects as a key mechanism for the emergence of team grit}

The individuals' grit might stimulate emotional contagion processes that lead to grit 'crossing over' from one team member to another (Bakker et al. 2009). Emotional contagion has been defined by Hatfield et al. (1993, p. 96) as "the tendency to automatically mimic and synchronize facial expressions, vocalizations, postures, and movements with those of another person and, consequently, to converge emotionally" (Bakker et al. 2009). Research on emotional contagion as well as on the crossover theory (Bakker 2005; Bakker et al. 2009; Westman 2001) demonstrates how affective states such as moods, as well as motivational emergent states such as work engagement can cross over from one individual to the other. Crossover and emotional contagion is more likely to occur when teams have a strong feeling of interdependency, and-building on Festinger's (1954) social comparison theory-when the individual observed is similar to them (Bakker et al. 2009). Social identity theory (Tajfel and Turner 1986) adds to the understanding of emotional contagion to occur when teams form by suggesting that the process whereby team members identify as a team is not just a behavioral, but also a cognitive and emotional process of alignment (Lembke and Wilson 1998).

Emotional contagion usually occurs in two successive steps (Barsade 2002; Hatfield et al. 1993). In the first step, an unconscious imitation of the emotion perceived via facial expressions, gestures or tone of voice takes place, which serves to synchronize with the person opposite. This emotional expression through imitation behavior in turn influences the own emotional state. Crossover theory adds to this non-conscious emotional contagion another way of "catching" someone else's emotions. Bakker et al. (2009) argue contagion to occur also via a conscious cognitive process of "tuning in" to the emotion of others. Contagion can occur for both negative and positive emotions (Paulsen and Kauffeld 2016; Westman 2001). Crucial for the contagion process is the energy level with which the emotion is expressed. This means that an emotion with a higher energy level — such as anger-has a stronger contagious power than an emotion with a lower energy level-such as a depressive mood (Barsade 2002).

Due to the proposed malleability of grit and the strong interdependence during innovation processes, we assume that the individual grit of team members can be affected over time due to contagion within the team. This is supported by an experimental study showing the influence of grit in a peer context (Gerhards and Gravert 2016). The study showed an individual's grit on a task to be affected by just observing another peer's grit in solving a task. The effect was strongest when the peers observed were similar to themselves in their task approach. Up to now, to our knowledge this effect has not been replicated in teams interacting on a task yet, neither for less well-defined tasks such as they are typical for innovation processes. We assume contagion can have an effect in both directions. When gritty people inspire others in the team with their commitment and conviction in pursuing goals, others' grit might be heightened. In contrast, when less gritty people pull others in the team down due to their lack of commitment and conviction for the goal, others' grit might be reduced.

In our above-described example, imagine the team in the brainstorming session, generating ideas for the onboarding program. If one team member shows a strong interest in the topic, exhibiting this visibly by being curious and passionate, persisting in finding ideas, other team members observing the team member displaying these emotions and behaviors might feel inspired to join in and also develop more passion about the topic. Imagine the team again receiving the negative feedback for their first draft of the buddy program. A team member taking the feedback in, asking curious questions and thus demonstrating a willingness to learn from the feedback and to adapt the behavior in consequence, might also affect the attitude and feeling with which the other team members approach the feedback. Both 
scenarios are also conceivable in the other direction, e.g. a team member demonstrating an obvious lack of interest in the topic might make others feel conscious about coming across as too passionate and they might ask themselves if their passion about the topic is valid. Thus, a downward spiral could be set in motion, leading team members' grit to decrease.

Contagion and crossover can hence contribute to the emergence of team grit, if an upward spiral is stimulated by team members high on grit. Research is needed to test this assumption and to specify how many team members high in grit it would need to set an upward spiral in motion.

In the next section, we explore both specific team processes within the team in different phases of an innovation process, as well as related emergent states that we argue to add to the emergence of team grit.

\subsection{The development of grit-The role of team processes and related emergent states}

For the emergence of team grit, we assume team processes, i.e. team member's interactions with each other (Marks et al. 2001), to be of fundamental relevance. The team interactions result in a shared environment for the team from which team grit may grow. Following Marks et al.'s (2001) taxonomy of team processes, we distinguish team processes by their occurrence in transition or action phases into either transition or action processes, as well as interpersonal processes that occur throughout both phases. We distinguish team processes from emergent states other than team grit that might also arise from those same team processes and have an influence on team grit and vice versa. We incorporate into this taxonomy of team processes the structure of innovation processes, starting with idea generation as the first action phase, followed by idea implementation as the second action phase (Anderson et al. 2014; Hülsheger et al. 2009), separated by transition phases (cf. Fig. 2). Thus, we expect the team processes that foster team grit to differ dependent on the time of their occurrence in the innovation process. As depicted in Fig. 2, interpersonal processes accompany the whole innovation process.
We start by defining the affective and cognitive emergent states, followed by a description of the team processes that we consider relevant for the emergence of team grit.

\subsubsection{Related emergent states}

As shown in Fig. 1, the team processes that foster team grit might equally foster other related affective and cognitive emergent states, while team grit relates to those emergent states in a dynamic and recursive way (Costa et al. 2014). We focus on four emergent states that may co-occur with team grit: shared interest, psychological safety, collective efficacy and shared mental models. Proposing a positive correlational relationship between those emergent states and team grit, we describe their role for team grit and their mutual influences in the following.

Shared interest Sharing the same work environment as a team can result in a group affective tone, i.e. team members sharing a common affective state due to contagion processes taking place in teams (Paulsen and Kauffeld 2016). Building on the notions of the "broaden-and-buildtheory of positive emotions" (Fredrickson 2001) that suggests that interest as a distinct positive emotion creates the urge for exploration behavior and the willingness to take in new information, we consider a shared interest as a group affective tone to be conducive for team grit to emerge. Interest as one of the 'psychological assets' Duckworth discusses leads to team members intrinsically enjoying what they do and is thus considered the foundation for passion to develop (Duckworth 2016). Hence, we assume a shared interest in the team to play into the team passion facet of team grit, facilitating focus on and exploration of the shared interest. Remember the manager's description of Team A in their brainstorming session, witnessing how they explored many different ideas for the onboarding program, seemingly enjoying digging deeper into their topic.

Psychological safety Psychological safety is an emergent state defined as a shared belief that it is safe to take interpersonal risks in the team (Edmondson 1999), resulting

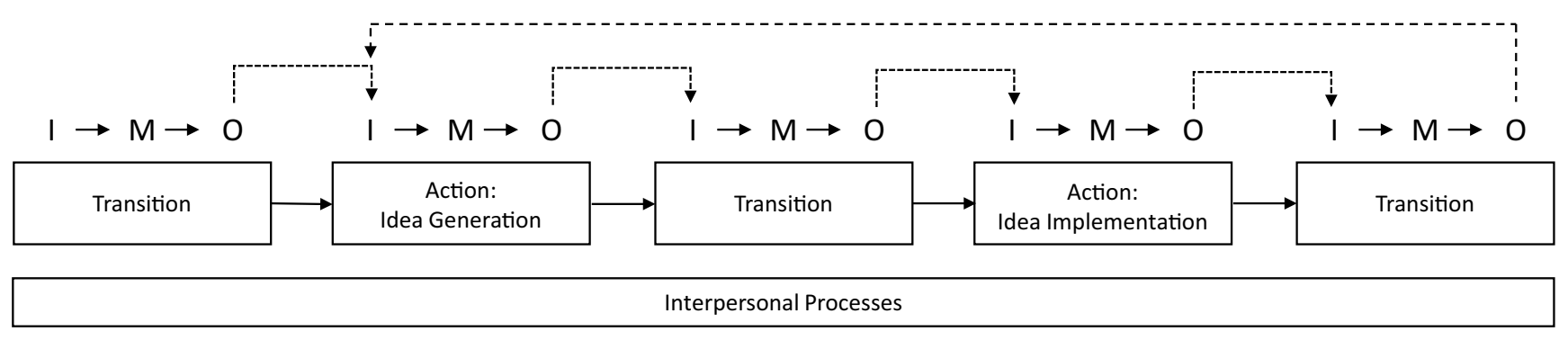

Fig. 2 The rhythm of team processes in the course of team innovation accomplishment (based on Marks et al. 2001). $I$ Team Input, $M$ Team Processes and Team Emergent States as Mediating Mechanisms, $O$ Team Output 
in team members openly admitting gaps in knowledge or mistakes, asking for help or advice and verbalizing premature ideas. Research shows that psychological safety affects the innovativeness of a team (Amabile and Pratt 2016). We assume psychological safety to influence team innovation via strengthening team grit. A psychologically safe team might display high levels of team passion and team perseverance, as they feel safe enough to explore and experiment with their topic of interest in depth and view making mistakes as part of the process, which keeps them going despite difficulties. Simultaneously, team grit might foster psychological safety. A gritty team might be more prone to exhibit behaviors such as asking curious questions and addressing difficulties that strengthen a psychologically safe climate. Team B in our example gave up their initial idea after having received negative feedback. We could imagine them not being open to discuss and look closer on to what they did not do well in the first place, resulting in them giving up their idea entirely instead.

Collective efficacy Bandura (1997, cited in Costa et al. 2014, p. 425) defined collective efficacy as the shared belief in a team that they will succeed in executing their tasks. Research shows collective efficacy to facilitate team performance, and there is research pointing to its relevance for innovative performance (Liu et al. 2015). On an individual level, evidence points to the relation of self-efficacy with grit (Muenks et al. 2018). At the team level, collective efficacy should facilitate the team's perseverance when facing difficulties by strengthening team members' trust in themselves to be able to deal with those. At the same time, the team's perseverance and the resulting progress experienced by persisting should strengthen collective efficacy. In our example, Team A reshapes their buddy program after receiving negative feedback. Adapting elements of their buddy program, they may start making progress and experience small successes soon, which we assume will strengthen their collective efficacy and which might strengthen their willingness to persevere.

Shared mental models A cognitive emergent state we propose to have an influence on team grit is a shared mental model within the team, i.e. shared cognitions about key elements in the team (Cannon-Bowers and Salas 2001). Research shows that shared mental models have a positive influence on team coordination, as they enable team members to accurately explain and form expectations with regard to other team members' behavior (Cannon-Bowers and Salas 2001; Stoverink et al. 2020). A shared task mental model (related to team goals, strategies and tasks) informs coordinated efforts to achieve the common goal. By increasing clarity and focus, team grit is fostered, so that the team does not sidetrack and invests its efforts wisely. With regard to the teams in our example, establishing a common understanding of what the onboarding program is supposed to achieve for the company may serve the team to check their prototypes against to see whether their idea is still on track. A shared team mental model (related to team members' interests and strengths) may contribute to the emergence of team grit specifically by affecting team passion. Knowing others' interests and expertise might facilitate team members to realize when and why team passion decreases and might give hints as to how to activate it again. Consequently, we assume shared mental models to affect team grit by facilitating focus, which plays into both team passion as well as team perseverance. Drawing on the Dual Pathway to Creativity Model, the enhanced focus should be particularly relevant in innovation processes (Nijstad et al. 2010).

Research is needed to test the relationships between team grit and the above-mentioned emergent states, as well as the influence of the team processes we explain in the next section on those emergent states.

\subsubsection{Team processes}

In the following, we describe the team processes we consider relevant for stimulating team grit. The selection of the following team processes relies on their proposed association with Duckworth's 'psychological assets' (interest, deliberate practice, purpose and hope) as well as their relevance for innovation. Marks et al.'s (2001) taxonomy serves as a structure, distinguishing between action and transition phase, as well as interpersonal processes. We start with interpersonal processes that occur throughout transition and action phases, and then describe team processes specific to transition or action phases.

Interpersonal processes Throughout both transition as well as action phases, interpersonal processes play a pivotal role in enhancing team outcomes, typically laying the foundation for the effectiveness of other team processes (Marks et al. 2001). We assume interpersonal processes to be of particular relevance for emotional contagion to take place, building on research identifying the team climate as a moderator for crossover effects (Bakker et al. 2009). Specific for the emergence of team grit, we propose open communication as well as mutual social support and motivation processes to help create a team climate enhancing the team's passion and perseverance. These interpersonal processes might build on all four 'psychological assets', activating interest and purpose, but also strengthening hope and triggering practice. We will describe those interpersonal processes in the following.

Open communication. Following Jordan et al.'s (2019) argumentation, we assume gritty teams to view negative feedback as a challenge rather than a hindrance. According 
to Duckworth, gritty individuals "hungrily seek feedback" (2016, p. 122), as a means to check whether they are still on track or whether they can improve. In Jordan et al.'s (2019) model, feedback constitutes a crucial element for task strategy adaptation. We expect open communication in teams, reflected in giving each other feedback on task performance, addressing issues and raising concerns when team members feel the work is not on track, to be pivotal for team grit. Imagine Team B of our example-if team members feel they cannot address issues with regard to the team's performance, they might "check out" mentally and not invest as much effort, decreasing team grit.

Social support \& motivation. The mutual social support as well as the motivation of each other act as the lubricant for team processes (Marks et al. 2001). Examples are positive encouragement in difficult situations, reminding each other of the respective strengths or engaging each other for the shared interests (Costa et al. 2014). We assume that by stimulating the shared interest and the team purpose, social support and motivation have an effect on team passion, while by strengthening hope in the sense of collective efficacy it triggers team perseverance. In our example, when having received the negative feedback for the first draft of the buddy program, team members encouraging each other to stay focused and to keep on trying, reminding each other of why (team purpose) what they work on matters, and actively supporting each other, should increase team grit.

Transition phase processes Based on Jordan et al.'s model (2019) pointing to the pivotal role of goal setting and task strategy adaptation, we assume the transition phases characterized by planning and evaluation activities to be crucial for the emergence of team grit. Taking into consideration the course of innovation processes, transition phase processes will take place before idea generation, in-between idea generation and idea implementation, and after idea implementation. As we do not assume innovation processes to follow a strict and well-defined pattern, those phases might be intertwined, with some idea generation happening in the midst of idea implementation (Anderson et al. 2014).

In the first transition phase - before idea generation begins-we consider team processes related to long-term goal setting, which establish a direction for the innovation process, to be most important. We expect team processes that play to the 'psychological assets' interest and purpose to build this context for team passion to emerge. For the creation of a shared interest, it is necessary to align team members' individual interests. Further, we expect the creation of a team purpose to add to this direction and thus strengthen team grit.

Interest alignment. Especially in new teams, teams benefit from team members getting to know each other's interests, competencies and preferences, which will help to align individual interests and strengths within the team. This interest alignment should result in a shared team mental model that facilitates focus and coordination (CannonBowers and Salas 2001), and the creation of a shared interest that provides team passion the foundation to emerge from. In our team example, this could mean asking for prior experiences in setting up an onboarding program, but also for each other's own experiences when joining the company. This should lead to a better picture of who can contribute what and by asking for own experiences it increases the feeling in every team member that they can contribute with their knowledge to the onboarding project, strengthening collective efficacy and activating their interest in the project.

Formation of a team purpose. Jointly forming an attractive team purpose, which builds on the team's shared interests and which states how the team interprets its charge for the future, can act as a compass for further actions to align with (Duckworth 2016; Marks et al. 2001). Following Duckworth's postulations, we assume the team purpose to be the most useful for guiding teams' activities when it is of a more abstract nature and considered as meaningful to the team (Duckworth and Gross 2014). The attraction of the purpose as well as the clear understanding thereof are the basis for team identification to take place (Lembke and Wilson 1998), which we assume essential for team grit to arise. Teams not agreeing on their team purpose risk misguiding their focus and effort-which would be harmful for team grit (Marks et al. 2001). To strengthen everyone's commitment to the team purpose, research suggests to develop it participatively (Locke and Latham 2006). A shared mental model regarding this team purpose should result out of this activity, which we assume will then facilitate to focus all further activities, supporting team grit to emerge. Again, imagine the teams in our example. If no team purpose is formed as to why the team matters, there is a risk that the ideas generated will not be focused. Some team members might generate ideas with the aim of assimilating newcomers to the company's culture as fast as possible, while others might aim at using newcomers as "fresh blood" to change the current company culture-aims arising from different perspectives on the team purpose. If different perspectives are not openly discussed, these could lead to conflicts and a drop in team passion.

In the second transition phase-after idea generation has taken place and before idea implementation begins-we expect the specification of short-term goals that lead to the accomplishment of the selected idea to facilitate the emergence of team grit. Setting challenging goals is an inherent part of deliberate practice-another 'psychological asset' Duckworth (2016) discussed as relevant for the development of grit on the individual level. As setbacks and difficulties are inevitable particularly during the course of idea 
implementation, an anticipation of and preparation for those adversities in the form of contingency plans may support the emergence of team grit via strengthening collective efficacy that we assume to be related to Duckworth's postulated 'psychological asset' hope.

Specification of short-term goals and task strategy planning. When having jointly agreed on an idea to pursue after idea generation, the goals to be achieved with this idea needs to be specified in order to orchestrate actions towards its accomplishment (Marks et al. 2001). Accordingly, specific task strategies for those short-term goals need to be planned. In terms of deliberate practice, challenging shortterm goals set clear milestones to achieve, which the team can use to measure their progress against. In our example, the first idea Team A wanted to implement was the development of a buddy program. In a next step, Team A plans how to implement this idea. Specifying elements of the buddy program act as short-term goals, and their achievement makes either progress or flaws in the plan visible.

Preparation for difficulties. In order to prevent a loss of performance in case of difficulties and setbacks, research suggests contingency planning in terms of the identification of possible obstacles and options for dealing with those as supportive. This process reduces uncertainty and prevents the team from encountering unnecessary unpleasant surprises (Marks et al. 2001). When actually encountering difficulties during the course of idea implementation, having prepared for foreseeable difficulties reduces the coordination effort in such a situation (Jordan et al. 2019; Stoverink et al. 2020). It also builds up Know-How on task strategies for potential difficulties that should strengthen collective efficacy (Costa et al. 2014). With regard to team grit, the preparation for difficulties should reduce the probability of the team becoming discouraged, giving it hope to be able to handle those difficulties effectively and keeping team perseverance up. In our example, imagining that Team A has come up with the idea of an online matching tool for assigning buddies to newcomers, they might anticipate how they would deal with the possibility that they will not be granted the requested financial resources and hence prepare alternatives.

The last transition phase concerns the phase after idea implementation, focusing on the evaluation of the outcomes and possibly leading to the next cycle of idea implementation when negative feedback is received and task strategies need to be adjusted. We assume team processes concerning team reflection to be useful in guiding the adaptive behavior needed in the following course of action.

Team reflexivity. Evaluating past performance and identifying adaptive behavior for future performance is a pivotal step for team performance (Schippers et al. 2014; Wiedow and Konradt 2011). Research demonstrates this reflection process in the team to be particularly relevant for team inno- vation (Schippers et al. 2015). During innovation processes, practicing translates into experimenting and the feedback after each experimentation represents a necessary condition for teams to evaluate their status quo and address weaknesses to work on in the future. In order to pay off to the asset deliberate practice, the focus of joint reflection should be on the learnings and the progress achieved, rather than on what has not been achieved yet (Duckworth 2016). Imagine Team A in our example working on the online matching tool for their buddy program and using weekly meetings to reflect on their progress on the task. We assume that making this progress transparent will strengthen team perseverance, as it brings the goal aspired into focus.

Action phase processes During action phases, teams conduct activities directed at goal accomplishment. While the transition phase before the action phase lays the foundation for those activities to be aligned, in action phases the team receives important feedback on whether the task strategies chosen guide towards goal accomplishment (Marks et al. 2001). With regard to innovation processes, idea generation is characterized by brainstorming, while idea implementation is characterized by experimenting with the implementation of the ideas chosen. We suggest team grit to affect team innovation during idea generation by strengthening focus and persistence while brainstorming, which following the argumentation of the Dual Pathway to Creativity Model (Nijstad et al. 2010) leads to more original ideas. During idea implementation, we suggest team grit to affect team innovation by having the team follow through despite difficulties, experiment with alternative task strategies to strive towards the long-term goal and not give up when encountering plateaus in progress.

Hence, for the first action phase as idea generation, the team needs to monitor the quality of the ideas generated while brainstorming and their contribution towards the accomplishment of the long-term goal.

Monitoring idea alignment toward long-term goals. For the persistence pathway as described by the Dual Pathway to Creativity Model (Nijstad et al. 2010) to be activated, teams need to stay focused on the long-term goal during their brainstorming sessions, generating as many ideas as possible in order to reach the more original ideas. The shared interest triggers the team passion necessary for keeping the team focused and exploring the area of interest in depth (Fredrickson 2001). Having established processes in the team that allow team members to monitor idea alignment may foster team grit, activating that shared interest and the team purpose. Imagine in our Team A the team having established team norms for those brainstorming sessions that guide their behavior and allow team members to intervene, such as "Generate as many ideas as possible!" or "Focus on the long-term goal!". 
In the second action phase-idea implementation, teams can stimulate their team passion and team perseverance by experimenting, monitoring progress and taking in immediate feedback. Experimental behavior and subsequent positive feedback is just as important as constructive criticism, which directs the focus to possible change strategies and thus leads to new experimentation (Jordan et al. 2019).

Experimentation behavior. Experimenting is useful for innovation processes due to teams needing to walk on new paths and thus not being able to base their behavior solely on past experiences. We assume experimentation behavior to be relevant for the emergence of team grit, as experimentation allows exploring the aspired goal, which should be behavior teams intrinsically enjoy and should add to the team's passion (Jordan et al. 2019). In our example, some elements of the online matching tool could be experimented with by adding new features and testing their added value for the tool. Team A intrinsically enjoys this exploration due to their shared interest in the topic, and thus fosters team passion.

Monitoring progress \& feedback. Monitoring progress goes hand in hand with the team reflection process proposed as a transition phase process, but differs from that by being a continuous process while performing the task. To foster collective efficacy, experiences of success and positive feedback are helpful (Amabile and Pratt 2016). According to Amabile's and Kramer's (2011) Progress Principle, the experience of making progress in pursuing goals is the most important amplifier of motivation and creativity (Amabile and Pratt 2016; Costa et al. 2014). Imagine Team A from our example working on the online matching tool. While working on specific features of the tool, they monitor how their previously agreed on task strategy works and give each other immediate feedback. They point out to each other the small successes they experience while making progress, which fuels their team grit, and makes them invest even more effort.

Team adaptation and learning Ultimately, the interplay of transition and action phase as well as interpersonal processes leads to team adaptation and learning. Throughout transition and action phases, adaptive processes take place that concern activities directly related to the change required due to difficulties, setbacks or negative feedback encountered (Christian et al. 2017). During idea implementation when the generated ideas are prototyped, experimentation behavior occurs. Experimentation behavior and the team's engagement "in activities that create iterative and shared action-reflection experiences" (Christian et al. 2017, p. 65) is supposed to lead to team learning, i.e. to the enhancement in knowledge and skills by the shared experience of the team members. Team adaptation and learning naturally occur during deliberate practice, encompassing experimentation followed by feedback. In our example, the team could learn from their experimentation with their buddy program with a pilot team of newcomers that expectations of a younger generation differ from the expectations of their own generation and thus add some features that would speak to the younger generation. This would be new knowledge acquired, deepening the expertise of the team performing and should contribute to team passion. Although team learning may be beneficial to team performance in general, it should play a particularly important role for team innovation, as experimenting with new ideas requires frequent shifts in response to new information or changed conditions (Amabile and Pratt 2016).

In summary, team processes link the team input-thus the individual grit of team members - to the emergence of team grit, and ultimately to team innovation. We propose the discussed team processes to add to team passion or team perseverance or both, either directly or via emergent states, which we assume to have a reciprocal relationship with team grit. Research is needed to validate the relevance of the described team processes for the emergence of team grit, and ultimately their influence on team innovation. Our list of team processes relies on their proposed association with Duckworth's 'psychological assets'. However, it might not be exhaustive and should hence be targeted by future research.

\section{Conclusions}

Our paper shows the relevance of team grit as a crucial innovation competence in today's dynamic working world. Innovation processes, which are vital for companies, are often lengthy. Under complex and volatile conditions, they require both a focus on the essentials, and stamina and endurance from teams-i.e., team grit.

We propose a model of team grit, which considers team processes as crucial antecedents of team grit. These team processes provide practitioners-managers as well as teams-with useful guidance on how to develop team grit within their teams, considering shared affective and cognitive states, such as collective efficacy and team goals, and their interactional nature. Grit is a competence that is worth promoting both on an individual and team level. By promoting individual grit, team grit can be strengthened through contagion and crossover processes taking place within the team. When selecting and developing team members to support team innovation processes, managers should thus consider grit in addition to professional competencies. In order for team grit to emerge, teams require common interactions and time spent together. Crucial for team grit as a dynamically developing team competence are 
joint team experiences, formed by specific team processes. Team processes, which build up shared team cognitions, such as a common task perception, seem to be as important as team processes, which contribute to the development of shared affective states, such as psychological safety, especially at the beginning of teamwork cycles. To further team grit and thus team innovation, it makes sense to establish a psychologically safe climate by dealing positively with mistakes and by giving mutual support. It is also helpful to stimulate and to build up collective efficacy by means of team reflection processes. In order to strengthen collective efficacy, it is crucial how the team experiences and deals with failure. It is important to focus on the learnings from failures, leading to necessary adaptation of behavior. In addition, teams should be supported in setting specific and challenging team goals, which are mutually supportive, and be given regular feedback on their progress towards these goals. It is essential to align each team members' own interests and goals with the focus goals and topics of the team, and to specify the meaning of own goals and tasks in relation to team goals. These team processes can be stimulated by the manager and with the support of coaches or mentors. They can also be built up by the team itself, which is particularly crucial for self-managing teams.

From a theoretical and methodological point of view, our model presents a starting point for research on team grit as a multilevel emergent state. Longitudinal designs may test for the proposed interactional nature of team grit with other related emergent states and team processes, as well as the proposed influence on team innovation. In addition, qualitative designs might detangle the interactions taking place within the team, allowing a closer look on the team processes at work.

Funding Open Access funding enabled and organized by Projekt DEAL.

Open Access This article is licensed under a Creative Commons Attribution 4.0 International License, which permits use, sharing, adaptation, distribution and reproduction in any medium or format, as long as you give appropriate credit to the original author(s) and the source, provide a link to the Creative Commons licence, and indicate if changes were made. The images or other third party material in this article are included in the article's Creative Commons licence, unless indicated otherwise in a credit line to the material. If material is not included in the article's Creative Commons licence and your intended use is not permitted by statutory regulation or exceeds the permitted use, you will need to obtain permission directly from the copyright holder. To view a copy of this licence, visit http://creativecommons.org/licenses/by/4. $0 /$.

\section{References}

Alan, S., Boneva, T., \& Ertac, S. (2019). Ever failed, try again, succeed better: results from a randomized educational intervention on grit. The Quarterly Journal of Economics, 134(3), 1121-1162.
Amabile, T. M., \& Kramer, S. J. (2011). The power of small wins. Harvard Business Review, 89(5), 70-80.

Amabile, T.M., \& Pratt, M.G. (2016). The dynamic componential model of creativity and innovation in organizations: making progress, making meaning. In Research in Organizational Behavior, 36, 157-183. https://doi.org/10.1016/j.riob.2016.10.001.

Amabile, T. M., Hill, K. G., Hennessey, B. A., \& Tighe, E. (1994). The work preference inventory: assessing intrinsic and extrinsic motivational orientations. Journal of Personality and Social Psychology, 66(5), 950-967.

Anderson, N., Potočnik, K., \& Zhou, J. (2014). Innovation and creativity in organizations. Journal of Management, 40(5), 1297-1333. https://doi.org/10.1177/0149206314527128.

Baas, M., Roskes, M., Sligte, D., Nijstad, B.A., \& De Dreu, C.K. (2013). Personality and creativity: the dual pathway to creativity model and a research agenda. Social and Personality Psychology Compass, 7(10), 732-748. https://doi.org/10.1111/spc3.12062.

Bakker, A. B. (2005). Flow among music teachers and their students: the crossover of peak experiences. Journal of Vocational Behavior, 66(1), 26-44. https://doi.org/10.1016/j.jvb.2003.11.001.

Bakker, A. B., Westman, M., \& van Emmerik, I. H. (2009). Advancements in crossover theory. Journal of Managerial Psych, 24(3), 206-219. https://doi.org/10.1108/02683940910939304.

Barsade, S. G. (2002). The ripple effect: emotional contagion and its influence on group behavior. Administrative Science Quarterly, 47, 644-675.

Cannon-Bowers, J.A., \& Salas, E. (2001). Reflections on shared cognition. Journal of Organizational Behavior, 22(2), 195-202.

Christian, J.S., Christian, M. S., Pearsall, M. J., \& Long, E. C. (2017). Team adaptation in context: an integrated conceptual model and meta-analytic review. Organizational Behavior and Human Decision Processes, 140, 62-89. https://doi.org/10.1016/j.obhdp.2017. 01.003 .

Costa, P.L., Passos, A.M., \& Bakker, A.B. (2014). Team work engagement: a model of emergence. Journal of occupational and organizational psychology, 87(2), 414-436. https://doi.org/10.1111/ joop. 12057.

Credé, M. (2018). What shall we do about grit? A critical review of what we know and what we don't know. Educational Researcher, 47(9), 606-611. https://doi.org/10.3102/0013189X18801322.

Credé, M., Tynan, M.C., \& Harms, P. D. (2017). Much ado about grit. A meta-analysic synthesis of the grit literature. Journal of personality and social psychology, 113(3), 492.

Disabato, D. J., Goodman, F. R., \& Kashdan, T. B. (2018). Is grit relevant to well-being and strengths? Evidence across the globe for separating perseverance of effort and consistency of interests. Journal of personality. https://doi.org/10.1111/jopy.12382.

Duckworth, A. L. (2016). Grit. The power of passion and perseverance. New York, London, Toronto, Sydney, New Delhi: Scribner.

Duckworth, A.L., \& Gross, J.J. (2014). Self-control and grit: related but separable determinants of success. Current directions in psychological science, 23(5), 319-325. https://doi.org/10.1177/ 0963721414541462.

Duckworth, A. L., \& Quinn, P.D. (2009). Development and validation of the short grit scale (grit-s). Journal of personality assessment, 91(2), 166-174. https://doi.org/10.1080/00223890802634290.

Duckworth, A.L., Peterson, C., Matthews, M.D., \& Kelly, D.R. (2007). Grit. Perseverance and passion for long-term goals. Journal of personality and social psychology, 92(6), 1087-1101. https://doi.org/10.1037/0022-3514.92.6.1087.

Duckworth, A.L., Kirby, T. A., Tsukayama, E., Berstein, H., \& Ericsson, K. A. (2011). Deliberate practice spells success. Social Psychological and Personality Science, 2(2), 174-181. https://doi. org/10.1177/1948550610385872.

Edmondson, A. (1999). Psychological safety and learning behavior in work teams. Administrative Science Quarterly, 44(2), 350. https:// doi.org/10.2307/2666999. 
Ericsson, K. A., Krampe, R.T., \& Tesch-Römer, C. (1993). The role of deliberate practice in the acquisition of expert performance. Psychological review, 100(3), 363-406.

Festinger, L. (1954). A Theory of Social Comparison Processes. Human Relations, 7 (2), 117-140.

Fredrickson, B. (2001). The role of positive emotions in positive psychology. American Psychologist, 56(3), 218-226.

Gerhards, L., \& Gravert, C. (2016). Because of you I did not give up-How peers affect perseverance. Working Papers in Economics, No 659. Gothenburg: University of Gothenburg.

Grohman, M. G., Ivcevic, Z., Silvia, P., \& Kaufman, S. B. (2017). The role of passion and persistence in creativity. Psychology of Aesthetics, Creativity, and the Arts, 11(4), 376-385. https://doi.org/ 10.1037/aca0000121.

Hammond, M.M., Neff, N.L., Farr, J.L., Schwall, A. R., \& Zhao, X. (2011). Predictors of individual-level innovation at work: a metaanalysis. Psychology of Aesthetics, Creativity, and the Arts, 5(1), 90-105. https://doi.org/10.1037/a0018556.

Hatfield, E., Cacioppo, J. T., \& Rapson, R. L. (1993). Emotional contagion. Current directions in psychological science, 2(3), 96-100.

Hill, P.L., Burrow, A.L., \& Bronk, K. C. (2016). Persevering with positivity and purpose: an examination of purpose commitment and positive affect as predictors of grit. Journal of Happiness Studies, 17(1), 257-269. https://doi.org/10.1007/s10902-014-9593-5.

Howard, M.C., \& Crayne, M.P. (2019). Persistence: defining the multidimensional construct and creating a measure. Personality and Individual Differences, 139, 77-89. https://doi.org/10.1016/j.paid. 2018.11.005.

Hülsheger, U.R., Anderson, N., \& Salgado, J.F. (2009). Team-level predictors of innovation at work. A comprehensive meta-analysis spanning three decades of research. The Journal of applied psychology, 94(5), 1128-1145. https://doi.org/10.1037/a0015978.

Ilgen, D.R., Hollenbeck, J.R., Johnson, M., \& Jundt, D. (2005). Teams in organizations. From input-process-output models to IMOI models. Annual review of psychology, 56, 517-543. https:// doi.org/10.1146/annurev.psych.56.091103.070250.

Jachimowicz, J. M., Wihler, A., Bailey, E. R., \& Galinsky, A. D. (2018). Why grit requires perseverance and passion to positively predict performance. Proceedings of the National Academy of Sciences of the United States of America, 115(40), 9980-9985. https://doi. org/10.1073/pnas.1803561115.

Jordan, S. L., Ferris, G. R., Hochwarter, W. A., \& Wright, T. A. (2019). Toward a work motivation conceptualization of grit in organizations. Group \& Organization Management, 44(2), 320-360. https://doi.org/10.1177/1059601119834093.

Kozlowski, S.W.J., Chao, G.T., Grand, J.A., Braun, M.T., \& Kuljanin, G. (2013). Advancing multilevel research design. Organizational Research Methods, 16(4), 581-615. https://doi.org/10. 1177/1094428113493119.

Lembke, S., \& Wilson, M.G. (1998). Putting the "team" into teamwork: alternative theoretical contributions for contemporary management practice. Human Relations, 51(7), 927-944.

Liu, J., Chen, J., \& Tao, Y. (2015). Innovation performance in new product development teams in China's technology ventures: the role of behavioral integration dimensions and collective efficacy. Journal of Product Innovation Management, 32(1), 29-44. https:// doi.org/10.1111/jpim.12177.

Locke, E. A., \& Latham, G.P. (2006). New directions in goal-setting theory. Current directions in psychological science, 15(5), $265-268$

Lucas, G. M., Gratch, J., Cheng, L., \& Marsella, S. (2015). When the going gets tough: grit predicts costly perseverance. Journal of Research in Personality, 59, 15-22. https://doi.org/10.1016/j.jrp. 2015.08.004.

Marks, M. A., Mathieu, J.E., \& Zaccaro, S.J. (2001). A temporally based framework and taxonomy of team processes. The Academy of Management Review, 26(3), 356-376.
Mooradian, T., Matzler, K., Uzelac, B., \& Bauer, F. (2016). Perspiration and inspiration. Grit and innovativeness as antecedents of entrepreneurial success. Journal of Economic Psychology, 56, 232-243. https://doi.org/10.1016/j.joep.2016.08.001.

Muenks, K., Yang, J. S., \& Wigfield, A. (2018). Associations between grit, motivation, and achievement in high school students. Motivation Science, 4(2), 158-176. https://doi.org/10.1037/mot0000076.

Nijstad, B.A., De Dreu, C.K.W., Rietzschel, E.F., \& Baas, M. (2010). The dual pathway to creativity model. Creative ideation as a function of flexibility and persistence. European review of social psychology, 21(1), 34-77. https://doi.org/10.1080/ 10463281003765323.

Park, H.H., Zhou, Y., \& Choi, M. (2018). When are individuals innovative? Journal of Personnel Psychology, 17(1), 1-11. https://doi. org/10.1027/1866-5888/a000190.

Paulsen, H. F. K., \& Kauffeld, S. (2016). Ansteckungsprozesse in Gruppen. Die Rolle von geteilten Gefühlen für Gruppenprozesse und -ergebnisse. Gruppe. Interaktion. Organisation. Zeitschrift für Angewandte Organisationspsychologie (GIO), 47(4), 357-364. https://doi.org/10.1007/s11612-016-0340-8.

Perkins-Gough, D. (2013). The significance of grit-a conversation with Angela Lee Duckworth. Educational Leadership, 71(1), 14-20.

Rimfeld, K., Kovas, Y., Dale, P.S., \& Plomin, R. (2016). True grit and genetics: predicting academic achievement from personality. Journal of personality and social psychology, 111(5), 780-789. https://doi.org/10.1037/pspp0000089.

Robertson-Kraft, C., \& Duckworth, A. L. (2014). True grit. Trait-level perseverance and passion for long-term goals predicts effectiveness and retention among novice teachers. Tech Coll Rec, 116(3).

Rousseau, V., Aubé, C., \& Tremblay, S. (2013). Team coaching and innovation in work teams. Leadership \& Organization Development Journal, 34(4), 344-364. https://doi.org/10.1108/LODJ-082011-0073.

Schippers, M.C., Edmondson, A.C., \& West, M. A. (2014). Team reflexivity as an antidote to team information-processing failures. Small Group Research, 45(6), 731-769. https://doi.org/10.1177/ 1046496414553473.

Schippers, M.C., West, M. A., \& Dawson, J.F. (2015). Team reflexivity and innovation. Journal of Management, 41(3), 769-788. https:// doi.org/10.1177/0149206312441210.

Stoverink, A.C., Kirkman, B.L., Mistry, S., \& Rosen, B. (2020). Bouncing back together: toward a theoretical model of work team resilience. AMR, 45(2), 395-422. https://doi.org/10.5465/amr. 2017.0005.

Suzuki, Y., Tamesue, D., Asahi, K., \& Ishikawa, Y. (2015). Grit and work engagement: a cross-sectional study. PloS one, 10(9), e137501. https://doi.org/10.1371/journal.pone.0137501.

Tajfel, H., \& Turner, J.C. (1986). The social identity theory of intergroup behavior. In S. Worchel and W. G. Austin (Eds.), Psychology of intergroup relations ( 2 nd ed.). Chicago: Nelson-Hall Publishers.

Westman, M. (2001). Stress and strain crossover. Human Relations, 54(6), 717-751.

Wiedow, A., \& Konradt, U. (2011). Two-dimensional structure of team process improvement: team reflection and team adaptation. Small Group Research, 42(1), 32-54. https://doi.org/10.1177/ 1046496410377358. 


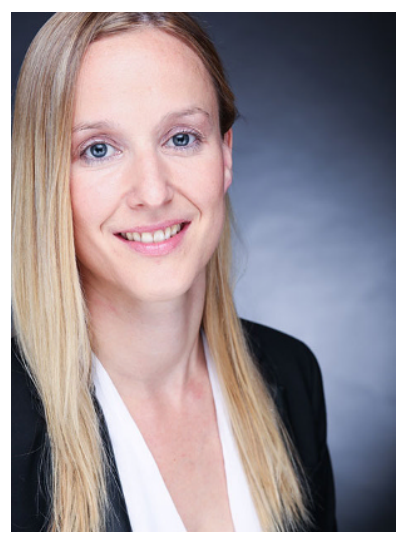

Dipl.-Psych. Valeria Bernardy is a research assistant in the Department of Work and Organizational Psychology at the University of Trier. She is currently working in the research project „,LLead“ on digital collaboration in teams and on her dissertation investigating the influence of team grit.

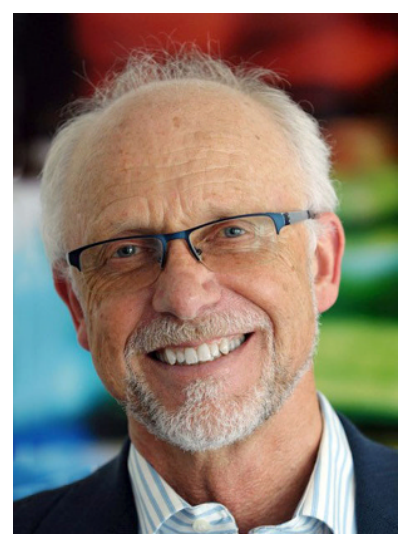

Prof. Dr. Conny H. Antoni is

Professor of Work and Organizational Psychology at the University of Trier. His research focuses on the topics teamwork, leadership, stress and work-life-balance, as well as reward and change management. 